All letters are subject to editing and may be shortened. Letters should be sent to the BJGP office by e-mail in the first instance, addressed to journalarcgp.org.uk (please include your postal address).

We regret that we cannot notify authors regarding publication. Letters not published in the Journal will be posted online on our Discussion Forum. For instructions please visit: http://www.rcgp.org.uk/bjgp-discuss

\section{Diagnosing type 2 diabetes and identifying high-risk individuals using the new glycated haemoglobin (HbA1c) criteria}

In the February 2013 issue of the BJGP there are several interesting and useful articles about aspects of diabetes, but I would like to question just one aspect stated in the Clinical Intelligence article by Gholap and colleagues. ${ }^{1}$

Basing diagnosis on an $\mathrm{HbA} 1 \mathrm{c}$ result has significant advantages, which are outlined in the article. They say that the $\mathrm{HbA1}$ c level reflects average glucose levels over the preceding 6-8 weeks (later giving the clinical situations in which that may not be the case). And they say that in a patient without symptoms any 'diagnostic' level test result needs to be repeated, or supported by another kind of test, to confirm a diagnosis with such important long-term implications. So-far-so-good. But I think it is incorrect to say that you can use an HbA1c level repeated just 2 weeks later. At this point the test result will largely cover exactly the same time period as the first, and thus it will confirm that the first test result was accurate. In order for it truly to be a 'second test' one needs to delay repeating $\mathrm{HbA1c}$ for at least $6-8$ weeks, so that the result reflects a different time period. This is a disadvantage of relying on HbA1c.

\section{Mick Leach,}

FRCGP, 28 Kings Road, Harrogate, HG15JP. E-mail: Mick.Leachlagp-b82013.nhs.uk

\section{REFERENCE}

1. Gholap NN, Davies MJ, Mostafa SA, Khunti K. Diagnosing type 2 diabetes and identifying high-risk individuals using the new glycated haemoglobin ( $\mathrm{HbA} 1 \mathrm{c})$ criteria. Br J Gen Pract 2013; DOI: 10.3399/bjgp13X663244.

DOI: 10.3399/bjgp13X665503
We read with interest Gholap et al's article on the diagnosis of type 2 diabetes mellitus (T2DM) using the new HbA1c criteria. ' We have been studying the diagnosis of T2DM in our general practice for several years. ${ }^{2}$

The diagnostic criteria for T2DM have long been set by the World Health Organization (WHO) and national guidelines. In 2011, WHO changed the diagnostic criterion to include an $\mathrm{HbA} 1 \mathrm{c}$ level of $48 \mathrm{mmol} / \mathrm{mol}$ (on two occasions if asymptomatic). ${ }^{3}$ The impact of this change has been debated, ${ }_{4}$ but not demonstrated in clinical practice. However, it does make it easier for GPs to arrange blood testing for people for whom fasting is practically difficult, and hence may increase the incidence of diabetes.

We have tracked the incidence of T2DM since our practice adopted the changed diagnostic criterion in November 2011. There were 23 new diagnoses in the last 9 months using the old criteria 161\% detected by screeningl compared with 59 in the same 9 months of the following year using the new criterion (73\% by screening). Thus the incidence rate increased from 2.95 to 7.46 per thousand $\left(\chi^{2}=15.32 ; P<0.001\right)$. This was a 2.5 fold increase in T2DM within the first year of using the new criterion.

The characteristics of patients diagnosed with type 2 diabetes in each of the time periods are summarised in Table 1 (available from the authors). Patients diagnosed after the change in diagnostic criterion were, on average, 9 years older $(P=0.03)$ but were similar in terms of their gender, $\mathrm{HbA} 1 \mathrm{c}$, and body mass index at diagnosis

This preliminary report appears to demonstrate a major increase in the incidence of diabetes using the new $\mathrm{HbAlc}$ criterion. This increase may be due to differing groups of patients being identified but may also be due to instances where patients with previous elevations of their HbA1c, but with normal blood glucose measurements, are now being retested and diagnosed. The implications are profound as diabetes currently takes $10 \%$ of all NHS hospital costs and $20 \%$ of all hospital beds. ${ }^{5}$

This may be a major advance enabling general practice to 'break into the iceberg' of undetected diabetes, or a new group of people with diabetes may be emerging.
The clinical impression of one of us $\mathrm{PH}$ Evans) is that more people are now being diagnosed with T2DM with substantial comorbidity, both physical and mental. We look forward to comparing diagnosis rates with colleagues.

Philip H Evans,

Senior GP Partner and Lead Researcher, St Leonard's Research Practice, Athelstan Road, Exeter, Devon, EX1 1SB.

E-mail: phil.evanslanhs.net

Denis J Pereira Gray,

Research Consultant, St Leonard's

Research Practice, Athelstan Road, Exeter, Devon.

Christine Wright,

Health Services Researcher, St Leonard's Research Practice, Athelstan Road, Exeter, Devon.

Peter Langley,

Research Assistant, St Leonard's Research Practice, Athelstan Road, Exeter, Devon.

\section{REFERENCES}

1. Gholap NN, Davies MJ, Mostafa SA, Khunti K. Diagnosing type 2 diabetes and identifying high-risk individuals using the new glycated haemoglobin ( $\mathrm{HbA} 1 \mathrm{c}$ ) criteria. Br J Gen Pract 2013; DOI: 10.3399/bjgp13X663244.

2. Evans PH, Langley P. Pereira Gray D. Diagnosing type 2 diabetes before patients complain of diabetic symptoms-clinical opportunistic screening in a single general practice. Fam Pract 2008; 25(5): 376-381.

3. World Health Organization. Use of glycated haemoglobin ( $\mathrm{HbAlC}$ ) in the diagnosis of diabetes mellitus: abbreviated report of a WHO consultation. Geneva: WHO, 2011.

4. Mostafa SA, Khunti K, Srinivasan BT, et al. The potential impact and optimal cut-points of using glycated haemoglobin, $\mathrm{HbA1c}$, to detect people with impaired glucose regulation in a UK multiethnic cohort. Diabetes Res Clin Pract 2010; 90(1): 100-108.

5. Alberti G, Gerada C, Hadley-Brown M, et al. Diabetes: 'we must act now'. The Times 2012; June 12: http://www.thetimes.co.uk/tto/opinion/ letters/article3442389.ece laccessed 8 Apr 2013)

DOI: 10.3399/bjgp13X665512 